\title{
Research on Optimization of Port Container Inland Collection and Distribution Network
}

\author{
Xuan Wang, ${ }^{1, *}$, Yun Jing ${ }^{1}$ \\ 1, ${ }^{*}$ School of Traffic and Transportation, Postgraduate, Beijing Jiaotong University, No.3 Shangyuancun, Haidian District, Beijing \\ 100044, China \\ ${ }^{1}$ School of Traffic and Transportation, Associate dean, Master Instructor, Beijing Jiaotong University, No.3 Shangyuancun, Haidian \\ District, Beijing 100044, China
}

\begin{abstract}
With the advancement of country's "the Belt and Road" strategy, each port is actively formulating development strategies to help implement the strategy. The port inland collection and distribution network is an important guarantee for the development of the port, and it is a key component to promote the connection between the port and the inland hinterland. It has an important role in expanding the scale of the port and improving the overall competitiveness of the port. Aiming at the current imbalance of the collection and distribution methods and the imperfect collection and distribution networks in most ports, this paper establishes an optimal model of collection and distribution network costs and quantitatively optimizes the collection and distribution network corridors. The Tianjin Port is selected as a case study object. And the MATLAB software is used to solve the analysis. The conclusion is that Tianjin Port could alleviate the pressure of the collection and distribution network by increasing the density of container trains with the hinterland cities, which verified the validity of the model.
\end{abstract}

\section{Introduction}

As an important node of "the Belt and Road", ports are an essential part of international shipping and play a pivotal role in connecting China's trade relations with countries along the route. As a major trading country in the world, $90 \%$ of the import and export trade is realized through the port collection and distribution system. With the advancement of the strategy, the throughput of the port has grown rapidly, and the optimization research of the collection and distribution network is also an urgent issue that the port needs to solve.

The optimization of the collection and distribution network mainly focuses on the path optimization, traffic optimization, and comprehensive network optimization. [1] introduced the shortest path optimization algorithm of multimodal transport network. Studying the impact of transportation costs on network competition from a general perspective is reflected in [2]. [3] proposed a mixed integer linear programming (MILP) model for the problem of network comprehensive optimization. The optimization research of collection and distribution from a system perspective is shown in [4]. Violeta et al. [5] evaluated the appropriate location of the intermodal terminal. [6] and [7] carried out optimization research on the collection and distribution railway corridors. At present, more attention is paid to the comprehensive transportation network between the port and the city where the port is located. There are few studies on the comprehensive optimization of the collection and distribution network extending to the inland hinterland. In recent years, due to the development of port logistics, the inland collection and distribution network between it and the hinterland cities has become more and more important. This article will optimize the container transportation network from this perspective.

The paper is organized as follows. In Section 2, study area, the problem of Tianjin Port's collection and distribution network is briefly introduced. After that, Section 3 explains how the optimization model are established. Then, Section 4 verifies the validity of the proposed model by using the example of Tianjin Port and conducts the experimental results. Finally, Section 5 summarizes the remarkable findings as well as the significance of research.

\section{Study area}

Tianjin Port is the largest comprehensive port in northern China, with more than 160 berths of various types. 103 of them are deep-water berths above 10,000 tons. In 2018, Tianjin Port's cargo throughput was 508 million tons, and its container throughput was 1600.69 TEU, ranking the fourth and ninth in the world's port throughput, respectively. At present, Tianjin Port has reached the requirements of international major ports in terms of terminal construction and modernization services. However, there are still some problems in the construction of the inland collection and distribution network, especially in the construction of transport corridors, which

\footnotetext{
* Corresponding author: 18120904@bjtu.edu.cn
} 
restrict the flow of goods between it and the inland hinterland. The main issues are as follows.

The first problem is the imbalance in the ratio of collection and distribution methods, and the proportion of railways is low. According to statistics, the proportion of various modes of transportation in Tianjin Port in recent years is shown in Table 1.

Table 1. Proportion of Tianjin Port freight transport.

\begin{tabular}{ccccc}
\hline & $\begin{array}{c}\text { Road } \\
\text { transport }\end{array}$ & $\begin{array}{c}\text { Rail } \\
\text { transport }\end{array}$ & $\begin{array}{c}\text { Water } \\
\text { transport }\end{array}$ & $\begin{array}{c}\text { Pipeline } \\
\text { transport }\end{array}$ \\
\hline $\begin{array}{c}\text { Bulk } \\
\text { cargo }\end{array}$ & $70 \%$ & $17 \%$ & $7 \%$ & $6 \%$ \\
$\begin{array}{c}\text { Container } \\
\text { cargo }\end{array}$ & $94 \%$ & $2 \%$ & $4 \%$ & - \\
\hline
\end{tabular}

Data source: Tianjin Statistics Bureau official website

Obviously, the sharing rate of the container collection and distribution network of Tianjin Port is extremely uneven, and the proportion of road transportation is too large. The railway has not exerted its advantages well. In terms of road collection and transportation, the main cargo source of Tianjin Port is close to the BeijingTianjin-Hebei region. Considering economic transportation distances, road collection and transportation occupies a certain advantage. For railway transportation, although the dry port and container train hub stations built in the hinterland cover a relatively large area, the functions of container train hub stations are not complete, and the number of railway transport channels and the number of open train stations is not large, resulting The capacity of railway collection and distribution is insufficient, so it cannot meet the needs of the inland hinterland.

Another prominent problem is the imperfect road transport network and the pressure on transportation. For the highway passage in Tianjin Port, there are fewer roads in the port area, and there is only one trunk road in the North Xinjiang Port Area. Most of the container road transportation needs to pass through urban roads in Tanggu District and connect with coastal highways. This behaviour leads to mixed passenger and freight traffic, causing traffic congestion, affecting the travel of urban residents, and increasing the pressure on urban roads, limiting the development of cities and ports. The highway network outside Hong Kong is relatively dense, with passages to Beijing, Northeast, Northwest, East and South China, but lacks direct passages in North, West and other directions, limiting communication with the Mainland.

\section{Model study}

The container inland collection and distribution network refers to a network system that collects and distributes container cargo through different modes of transportation, and generally occurs within a specific area of a port [8]. The specific structure of the collection and distribution network is shown in Fig. 1. Optimizing it is a problem that most ports need to face. For the entire network, it is constructed and optimized to maintain efficient continuity throughout the transportation of container cargo, thereby improving its service level and meeting the needs of container transportation in various regions. The article will consider satisfying the future container demand, and optimize the transportation channel with the goal of minimizing the total collection and distribution costs to meet the needs of container owners for transportation time and costs.

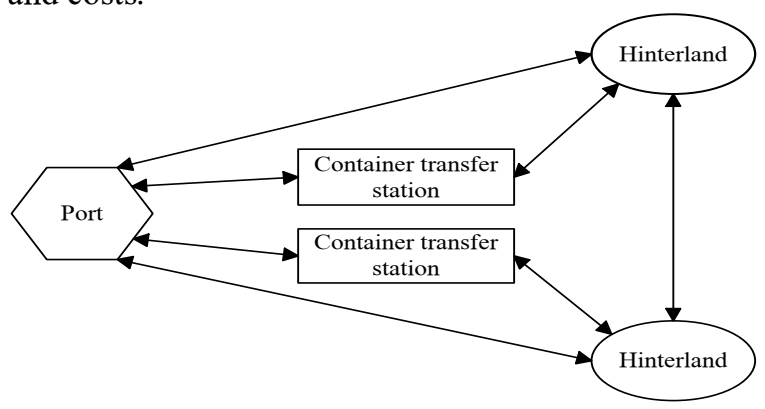

Fig. 1. Container cargo collection and distribution network.

\subsection{Model assumptions}

(1) The container throughput is based on the total number of containers entering and leaving the port and loading and unloading. It is a problem of two-way flow of container cargo. This article considers that the flow of container cargo is the transit transportation from the port through the container transfer station to the inland hinterland cities and the direct transportation from the port to the inland hinterland cities, without considering reverse transportation.

(2) The transportation channels of the collection and distribution network mainly include railway channels, highway channels and waterway channels. The optimization model in this paper considers the choice of transport passages between ports and inland cities. Waterway passages are subject to certain limitations due to their geographical location and natural conditions, and are not considered here.

(3) It is assumed that the processing capacity of each node, such as loading, unloading, receiving, and inventory, can meet the demand for freight volume.

(4) For the convenience of calculation, the paper unified container is a 20 -foot standard container, and the calculation unit is TEU.

\subsection{Model variables and parameters}

Decision variables of the model are explained below:

$x_{i j}^{r}=$ container volume from port $i$ to container transfer station $j$ by mode $r$,

$y_{j k}^{r}=$ container volume from container transfer station $j$ to inland hinterland city $k$ by mode $r$,

$z_{i k}^{r}=$ container volume from port $i$ to inland hinterland city $k$ by mode $r$,

State variables and related parameters introduced in the model are explained below:

$r=$ mode of collection and distribution transport, the value of 1 indicates rail transport, and the value of 2 indicates road transport,

$f_{i j}^{r}=$ unit container transport cost from port $i$ to container transfer station $j$ by mode $r$, 
$f_{j k}^{r}=$ unit container transport cost from container transfer station $j$ to inland hinterland city $k$ by mode $r$,

$f_{i k}^{r}=$ unit container transport cost from port $i$ to inland hinterland city $k$ by mode $r$,

$c_{i j}^{r}=$ unit container shipping time cost rom port $i$ to container transfer station $j$ by mode $r$,

$c_{j k}^{r}=$ unit container shipping time cost from container transfer station $j$ to inland hinterland city $k$ by mode $r$,

$c_{i k}^{r}=$ unit container shipping time cost from port $i$ to inland hinterland city $k$ by mode $r$,

$q_{k}=$ container demand for inland hinterland city $k$,

$p_{i j}^{r}=$ the maximum volume of container from port $i$ to container transfer station $j$ by mode $r$,

$p_{j k}^{r}=$ the maximum volume of container from container transfer station $j$ to inland hinterland city $k$ by mode $r$,

$p_{i k}^{r}=$ the maximum volume of container from port $i$ to inland hinterland city $k$ by mode $r$,

$A=$ ports collection, $A=\left\{A_{i} \mid i=1,2,3, \ldots, l\right\}$,

$B=$ container transfer station collection $B=$ $\left\{B_{j} \mid j=1,2,3, \ldots, m\right\}$,

$C=$ Inland hinterland cities collection $C=$ $\left\{C_{k} \mid k=1,2,3, \ldots, n\right\}$

\subsection{Model establishment}

The inland collection and distribution network optimization model is established as follows:

$$
\begin{gathered}
\min Z=\sum_{i=1}^{l} \sum_{j=1}^{m} \sum_{r=1}^{2}\left(f_{i j}^{r}+c_{i j}^{r}\right) x_{i j}^{r}+ \\
\sum_{j=1}^{m} \sum_{k=1}^{n} \sum_{r=1}^{2}\left(f_{j k}^{r}+c_{j k}^{r}\right) y_{j k}^{r}+\sum_{i=1}^{l} \sum_{k=1}^{n} \sum_{r=1}^{2}\left(f_{i k}^{r}+c_{i k}^{r}\right) z_{i k}^{r} \\
\sum_{i=1}^{l} \sum_{r=1}^{2} x_{i j}^{r}=\sum_{k=1}^{n} \sum_{r=1}^{2} y_{j k}^{r}, \forall j=1,2,3, \ldots, m \\
\sum_{i=1}^{l} \sum_{r=1}^{2} z_{i k}^{r}+\sum_{j=1}^{m} \sum_{r=1}^{2} y_{j k}^{r}=q_{k}, \forall k=1,2,3, \ldots, n(3) \\
x_{i j}^{r} \leq p_{i j}^{r}, \forall i=1,2,3, \ldots, l, j=1,2,3, \ldots, m, r=1,2 \\
y_{j k}^{r} \leq p_{j k}^{r}, \forall j=1,2,3, \ldots, m, k=1,2,3, \ldots, n, r=1,2 \\
z_{i k}^{r} \leq p_{i k}^{r}, \forall i=1,2,3, \ldots, l, k=1,2,3, \ldots, n, r=1,2 \\
x_{i j}^{r}, y_{j k}^{r}, z_{i k}^{r} \geq 0, x_{i j}^{r}, x_{j k}^{r}, x_{i k}^{r} \in Z^{+}
\end{gathered}
$$

The objective function (1) consists of the sum of the costs for container inland collection and distribution, including transportation and time costs. Constraint (2) ensure that the amount of container in and out of the container transfer station is equal, that is, the container cargo does not remain. Constraint (3) means that the container volume from each port to transit inland hinterland cities through transit and direct transportation meets its container demand. The traffic limitation of transport from port $i$ to container transfer station $j$ by mode $r$ is shown by constraint (4). The traffic limitation of transport from container transfer station $j$ to inland hinterland city $k$ and from port $i$ to inland hinterland city $k$ by mode $r$ are given by constraint (5) and (6), respectively. Constraint (7) indicates that the container shipments are all integers greater than or equal to zero. If the container transfer station $j$ and the inland hinterland city $k$ represent an urban area, the sum of the traffic volume between the port and the container transfer station and the hinterland city should be less than the traffic limit between the port and the hinterland city.

\section{Model application}

\subsection{Case study}

According to the dry port of Tianjin Port and the hinterland, two regional marketing centers in Shijiazhuang and Baotou were selected as container transfer stations. Inland hinterland cities were selected as Beijing, Shijiazhuang, Zhangjiakou, Taiyuan, Datong, Baotou, and Hohhot. The specific container inland collection and distribution network is shown in Fig. 2.

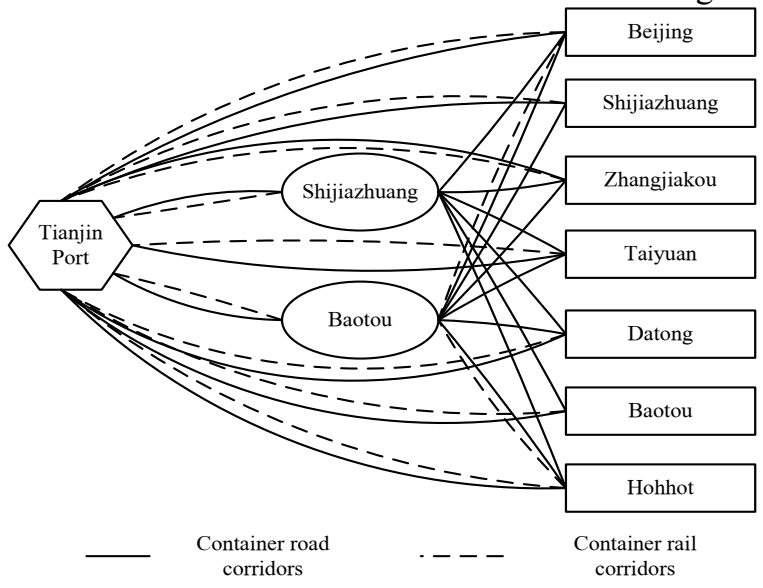

Fig. 2. Tianjin Port container inland collection and distribution network.

According to the planning situation of Tianjin, 2022 is taken as the planning year, and the BP neural network prediction method is used to predict the container throughput of Tianjin Port in 2022. The results show that the container throughput of Tianjin Port is expected to

\begin{tabular}{|c|c|c|c|c|c|c|c|c|c|}
\hline & Constraints & & Beijing & Shijiazhuang & Zhangjiakou & Taiyuan & Datong & Baotou & Hohhot \\
\hline \multirow{2}{*}{$\begin{array}{l}\text { Distance } \\
\text { from } \\
\text { container }\end{array}$} & \multirow{2}{*}{ Shijiazhuang } & Rail & - & - & - & - & - & - & - \\
\hline & & Road & 292 & - & 417 & 224 & 470 & 612 & 614 \\
\hline
\end{tabular}
reach 18.463 million TEUs by 2022. According to the selected collection and distribution nodes, basic data of the hinterland cities, basic data of container transfer stations, container collection and distribution freight, and collection and distribution channel basic data are shown in Table 2-5.

Table 2. Basic data of hinterland cities. 


\begin{tabular}{|c|c|c|c|c|c|c|c|c|}
\hline $\begin{array}{l}\text { transfer } \\
\text { station to }\end{array}$ & Rail & 467 & - & - & - & - & - & 167 \\
\hline $\begin{array}{c}\text { inland } \\
\text { hinterland } \\
\text { city / km }\end{array}$ & Road & 482 & 612 & 482 & 437 & 408 & - & 186 \\
\hline \multirow{2}{*}{$\begin{array}{l}\text { Distance from Tianjin Port to } \\
\text { hinterland city / km }\end{array}$} & Rail & 137 & 387 & 316 & 824 & 499 & 824 & 602 \\
\hline & Road & 147 & 339 & 327 & 794 & 511 & 794 & 614 \\
\hline Container demand / TEU & & 4590746 & 3891625 & 2004776 & 1718464 & 736484 & 1730985 & 741851 \\
\hline
\end{tabular}

Table 3. Basic data of container transfer station.

\begin{tabular}{cccc}
\hline Constraints & & Shijiazhuang & Baotou \\
\hline Distance from Tianjin & Rail & 387 & 824 \\
Port to Container Transit & Road & 339 & 794 \\
Station / km & . & \\
\hline
\end{tabular}

Table 4. Container collection and distribution costs.

\begin{tabular}{cccc}
\hline \multirow{2}{*}{ Cost } & Mode of & \multicolumn{2}{c}{ Precise data } \\
\cline { 3 - 4 } & transport & $\begin{array}{c}\text { Fixed costs } \\
\text { (yuan / } \\
\text { TEU) }\end{array}$ & $\begin{array}{c}\text { Variable cost } \\
\text { (yuan / km / } \\
\text { TEU) }\end{array}$ \\
\hline $\begin{array}{c}\text { Transportation } \\
\text { costs }\end{array}$ & Road & 50 & 6 \\
Time costs & Rail & 789.3 & 1.5830 \\
& Road & 74.5 & 0.0326 \\
\hline
\end{tabular}

Table 5. Basic data of collection and distribution corridors.

\begin{tabular}{cc}
\hline Railway corridors & Maximum capacity / (TEU) \\
\hline Tianjin-Shijiazhuang & 67200 \\
Tianjin-Baotou & 53760 \\
Baotou-Beijing & 53760 \\
Baotou-Hohhot & 40320 \\
Tianjin-Beijing & 40320 \\
Tianjin-Zhangjiakou & 53760 \\
Tianjin-Taiyuan & 53760 \\
Tianjin-Datong & 40320 \\
Tianjin-Hohhot & 40320 \\
\hline
\end{tabular}

The data sources are mainly the official websites of Tianjin Port Co., Ltd., the Communications Bureau, the National Bureau of Statistics and the Railway Bureau.

\subsection{Model results}

The collated data is substituted into the model and solved by MATLAB software. The specific results are shown in Tables 6-9.

Table 6. Proportion of collection and distribution methods.

\begin{tabular}{cc}
\hline Mode of transport & Proportion \\
\hline Rail & $98.19 \%$ \\
Road & $1.81 \%$ \\
\hline
\end{tabular}

Table 7. Proportion of direct and transit transportation.

\begin{tabular}{cc}
\hline Transport method & Proportion \\
\hline Direct transportation & $89.20 \%$ \\
Transit transportation & $10.80 \%$ \\
\hline
\end{tabular}

Table 8. Direct transport container volume. (Unit: TEU)

\begin{tabular}{ccc}
\hline Inland hinterland & Rail & Road \\
\hline Beijing & 0 & 4590746 \\
Shijiazhuang & 0 & 3891625 \\
Zhangjiakou & 53760 & 1951016 \\
Taiyuan & 53760 & 0 \\
Datong & 40320 & 696164 \\
Baotou & 53760 & 1677225 \\
Hohhot & 40320 & 701531 \\
\hline
\end{tabular}

Table 9. Transit transport container volume. (Unit: TEU)

\begin{tabular}{cccc}
\hline \multirow{2}{*}{ Port } & $\begin{array}{c}\text { Mode of } \\
\text { transport }\end{array}$ & $\begin{array}{c}\text { Container } \\
\text { transfer station }\end{array}$ & $\begin{array}{c}\text { Inland } \\
\text { hinterland }\end{array}$ \\
\cline { 3 - 4 } & Shijiazhuang & Taiyuan \\
\hline $\begin{array}{c}\text { Tianjin } \\
\text { Port }\end{array}$ & Rail & 67200 & 0 \\
\hline
\end{tabular}

\subsection{Result analysis}

From the model results in the previous section, it can be seen that under the current collection and distribution network, the future container transportation mode of Tianjin Port will be mainly highways, accounting for $98.19 \%$. Further analysis of the results found that no matter whether it is direct or transit transportation, the sections with railway traffic have reached saturation. This will affect the choice of container cargo for rail transportation, which will increase the collection and distribution costs. Therefore, this section will release railway traffic restrictions.

First of all, removing the railway traffic restriction constraints found that the railway traffic has been greatly improved. Railway transportation accounts for $70.22 \%$, and direct transportation has been selected between Tianjin Port and inland hinterland cities. This shows that Tianjin Port should consider improving the railway channel with direct access to the hinterland. Taking into 
account the reality of the situation, the removal of railway traffic constraints need to invest in the expansion of railway facilities, potentially increasing input costs, and the development of a single road transport or rail transport will lead to efficiency, waste of resources. Therefore, from the perspective of balanced road and railway traffic, this paper appropriately enlarges the railway restrictions and gives an optimization plan.

After several trial calculations, a relatively balanced result will be reached when the railway limit is expanded by a factor of 30 . Railway transportation accounted for $49.17 \%$. The results after releasing the constraints are shown in Table 10 and Table 11.

Table 10. Direct transport container volume after releasing the constraints. (Unit: TEU)

\begin{tabular}{ccc}
\hline Inland hinterland & Rail & Road \\
\hline Beijing & 0 & 4590746 \\
Shijiazhuang & 1209600 & 2682025 \\
Zhangjiakou & 1612800 & 391976 \\
Taiyuan & 1612800 & 0 \\
Datong & 736484 & 0 \\
Baotou & 1612800 & 118185 \\
Hohhot & 741851 & 0 \\
\hline
\end{tabular}

Table 11. Transit transport container volume after releasing the constraints. (Unit: TEU)

\begin{tabular}{cccc}
\hline \multirow{2}{*}{ Port } & $\begin{array}{c}\text { Mode of } \\
\text { transport }\end{array}$ & $\begin{array}{c}\text { Container } \\
\text { transfer station }\end{array}$ & $\begin{array}{c}\text { Inland } \\
\text { hinterland }\end{array}$ \\
\cline { 3 - 4 } & Shijiazhuang & Taiyuan \\
\hline $\begin{array}{c}\text { Tianjin } \\
\text { Port }\end{array}$ & Rail & 105664 & 0 \\
\hline
\end{tabular}

At this time, the total cost of collection and distribution was 30.232 billion yuan, which is $18.3 \%$ lower than the total cost of 36.889 billion yuan before release. According to the optimization results, except for the density of container trains between Tianjin and Beijing, the density of other trains between the hinterland and Tianjin needs to be increased. The calculation results of specific increase factors are shown in Table 12.

Table 12. Increase in the density of trains.

\begin{tabular}{cc}
\hline Railway corridors & Increase multiples \\
\hline Tianjin-Shijiazhuang & $(105664+1209600)$ \\
Tianjin-Zhangiiakou & $1612800 / 53760=30$ \\
Tianjin-Taiyuan & $1612800 / 53760=30$ \\
Tianjin-Datong & $736484 / 40320=18.2$ \\
Tianjin-Baotou & $161280 / 53760=30$ \\
Tianjin-Hohhot & $741851 / 40320=18.4$ \\
\hline
\end{tabular}

In order to solve the problems of the container inland collection and distribution network of Tianjin Port, it is necessary to strengthen the construction of railway transportation channels or increase the frequency of trains, thereby increasing the density of container trains between Tianjin Port and the inland hinterland, and increasing railways. It not only solves the problem that railway transportation accounts for a relatively small amount, but also reduces the burden of road transportation to a certain extent.

\section{Conclusions}

The research on the optimization of inland collection and distribution network is an emerging topic, which has strong theoretical and practical significance. With the changes in the regional economic structure and the logistics services of major ports along the coast are gradually penetrating deeper into the inland, new measures have been continuously taken to link the relevant ports with the inland. If the port continues to use the traditional management method, it will lag behind the needs of the development of the situation. Therefore, it is necessary and practical to optimize the inland collection and distribution network of the port. The core content of this article is to build an optimization model and do an empirical analysis for the transportation channel problem in the collection and distribution network. The problems in Tianjin Port's inland collection and distribution network are analysed, and the optimization model analysis is used to conclude that Tianjin Port can alleviate the pressure of the collection and distribution network by increasing the container train density with the hinterland cities. It is hoped that through the optimization analysis of the inland collection and distribution network of Tianjin Port, it will provide some reference for the optimization of the inland collection and distribution network of relevant ports, and help to reduce the operating cost of the entire collection and distribution network and improve the competitiveness of the port.

\section{Acknowledgement}

This study is Supported by National Key R\&D Program of China (2018YFB1201401); the Fundamental Research Funds for the Central Universities (2019JBM030).

\section{References}

1. A. Lozano, G. Storchi, TRANSPORT RES A-POL, 35 (2001)

2. M. Janic, TRANSPORT RES D-TRE, 12 (2006)

3. T. Chang, COMPUT OPER RES, 35, 2877-2891 (2008)

4. R. Xiao, TRANSP ECON, 53-57 (2011)

5. V. Roso, N. Brnjac, B. Abramovic, 54, 496 (2015)

6. W. Pan, TRANSP ECON, 40, 80-84 (2018)

7. Y. Sun, TRANSP ECON, 41, 10-15 (2019)

8. X. Yue, Z. Yin, Z. Wu, TRANSP ECON, 41, 115-120 (2019) 